\title{
Mechanical and thermal properties of cockles shell cementing material
}

\author{
Aseel Basim Al-Zubaidi ${ }^{1}$, Ragad U. Abass ${ }^{1}$, Ahmed A. Al-Tabbakh', \\ Nazar Jabbar Abdulridha ${ }^{1}$ \\ ${ }^{1}$ Department of Material Engineering, University of Technology, Al-Sinaa Street, Baghdad, Iraq \\ ${ }^{2}$ Department of Physics, College of Science, Al-Nahrain University, Jadiriya, Baghdad, Iraq
}

E-mail: dr.material@yahoo.com

\begin{abstract}
Mortar of ordinary Portland cement was blended with cockles shell powder at different weight ratios to investigate the effect of powder admixture on their strength and thermal conductivity. Results showed that addition of cockles shell powder at $50 \%$ of mortar weight improves hardness and compressive strength notably and reduces the thermal conductivity of the end product. Results suggest the possibility to incorporate cockles shell powders as constituents in cement mortars for construction and plastering applications.
\end{abstract}

\author{
Key words \\ Cementing materials, \\ Composites, Cockles \\ shell, Mechanical \\ properties.
}

Article info.

Received: Jun. 2014

Accepted: Aug. 2014

Published: Apr. 2015

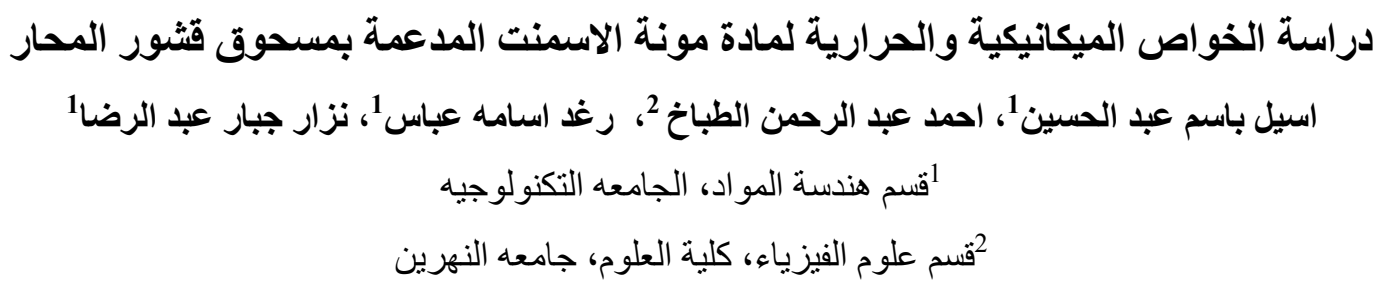

تم خلط مونة الاسمنت البورتلاندي العادي مع مسحوق قثشور المحار بنسب وزنبه مختلفة لدر اسة تأثير الخليط من مسحوق

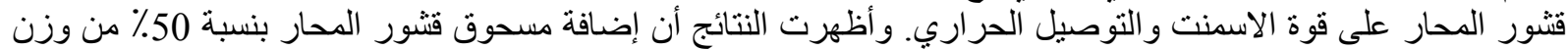

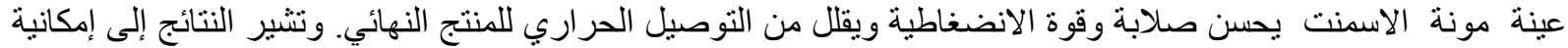
خلط في شكل مكونات لمونه الاسمنت للبناء و التطبيقات التجصيص.

\section{Introduction}

Cockle and Oyster shells are known for their notable mechanical and thermal properties attributed to morphological (crystalline) and elemental structures. They are generally composed of calcium carbonate of prismatic layers giving the shell structure a high strength, low mass and low coefficient of heat conductivity [1-3]. Due to their compositional structure, these shells were considered low-cost sources for substitution of cement clinker or as substitutes of some cement mortar constituents. Chemical and microstructure analyses of crushed oyster shells have been investigated by Gil-Lim Yoon et al. showing the possibility of using the oyster shell powders in construction materials particularly in cement mortar [4,5]. Shells treatment and processing effects on mechanical properties of concrete, investigated by Pusit et al., suggest that 
ground seashells can be applied as a cement replacement in mortar mixes and may improve the workability of rendering and plastering mortar [3].

Workability and compressive strength of concrete containing different ratios of cockle shell content as partial coarse aggregate replacement was investigated recently showing the possibility to produce a workable concrete after mixing with cockles shells powder and improvement of compressive strength [6]. In the present work investigation of cockles shell powder on Portland mortar is investigated based on different mixing ratios of this powder in the prepared mortar. Our current investigation is further extended to investigate the effect of the powder admixture on the hardness and the thermal conductivity of the cured mortars.

\section{Materials and methods}

Cockle shells waste were collected from Kapar in Malaysia. The shells were washed thoroughly with water to remove dirt and dried in oven at $100{ }^{\circ} \mathrm{C}$ for 2 hours (see Fig. 1). The clean shells were primarily crushed to small pieces using JFSD - 100 crusher. The crushed shells were then subjected to a dry ball milling at $200 \mathrm{rpm}$ for 24 hours to produce a fine powder with particle size $(0.6 \mu \mathrm{m})$ which is shown in Fig.2. The produced powder was then subjected to particle size measurement, $\mathrm{X}$-ray diffraction and X-ray fluorescence analyses to investigate its physical and compositional structures. Details of principles of particle size distribution measurements are found elsewhere [7]. A small amount of the cockles shells powder were dispersed in water using a sonicator for 10 minutes. Laser diffraction particle size analyzer (SALD 2101 from Shimadzu) was used for the size distribution measurement. The XRD measurements were achieved using X-ray diffractometer from Shimadzu while XRF measurements were performed using Niton XLT-800 XRF analyzer. The cockles' shells powders are used as admixture to standard Portland cement (grain size $53 \mu \mathrm{m}$ ). The ratio of the cockles shell powder to other compositions for four different samples is shown in Table 1. The final weight of each prepared sample is $24 \mathrm{~g}$. All samples were pressed to pellets of $2 \mathrm{~cm}$ diameter each under a pressure of 15 tons for 20 seconds. All samples were immersed in water for one hour and subsequently dried for 12 hours and this was repeated for several times over two weeks to achieve a desirable hardness in the samples due to cementing reaction. The prepared samples were then characterized to investigate the effect of the cockles' powder ratio on the mechanical properties (hardness and compression) and thermal conductivity of the end product.

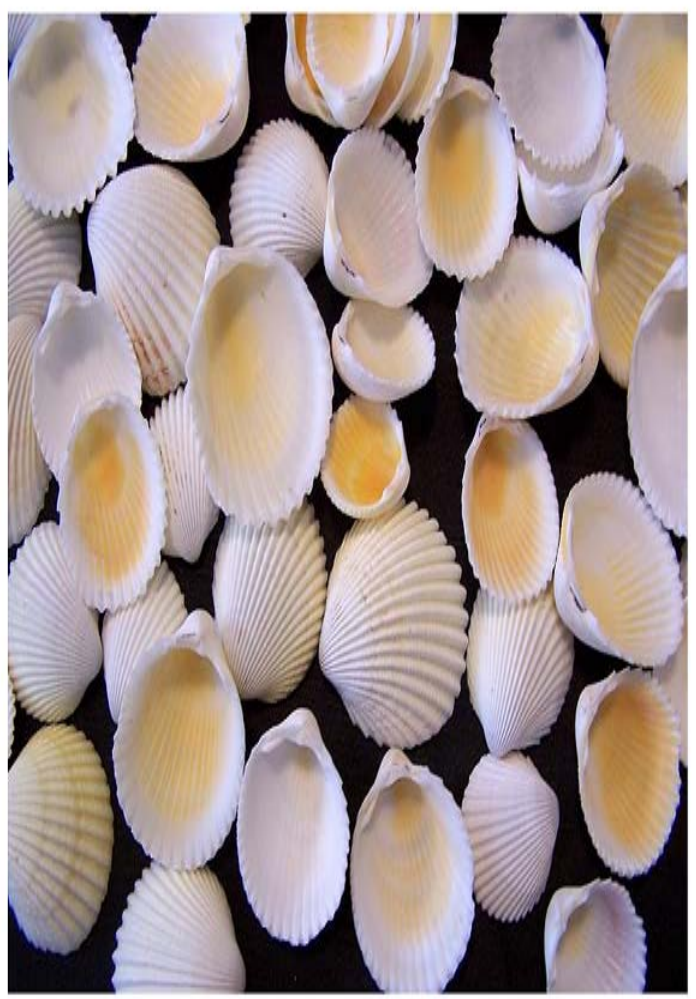

Fig. 1: Cockles shells as collected and washed. 


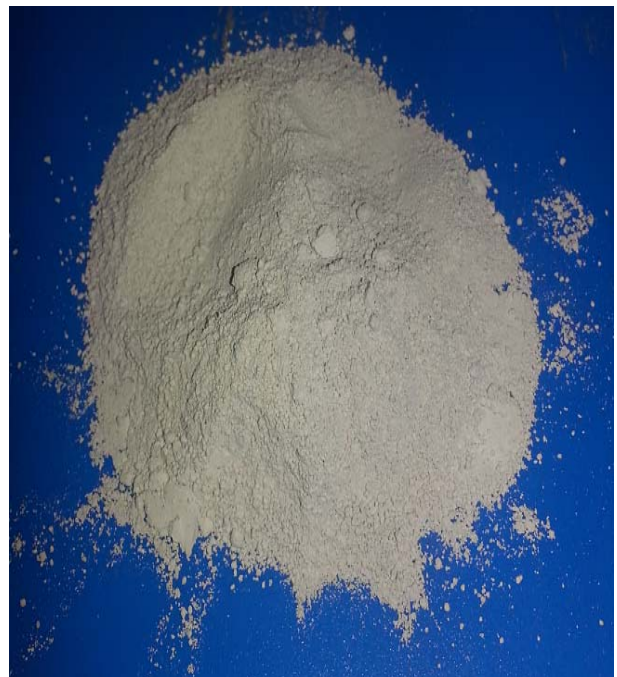

Fig. 2: Powder of cockles shells obtained by ball milling of crushed shells.

Table 1: Ratios of components of prepared mortars.

\begin{tabular}{|l|l|l|l|l|}
\hline & \multicolumn{3}{|l|}{ Component percentage } & \\
\hline $\begin{array}{l}\text { Sample } \\
\text { number }\end{array}$ & $\begin{array}{l}\text { Cockles } \\
\text { shell } \\
\text { powder }\end{array}$ & Sand & Cement & Water \\
\hline$\# 1$ & $0 \%$ & $25 \%$ & $75 \%$ & $4 \mathrm{ml}$ \\
\hline$\# 2$ & $10 \%$ & $25 \%$ & $65 \%$ & $4 \mathrm{ml}$ \\
\hline$\# 3$ & $25 \%$ & $25 \%$ & $50 \%$ & $4 \mathrm{ml}$ \\
\hline$\# 4$ & $40 \%$ & $25 \%$ & $35 \%$ & $4 \mathrm{ml}$ \\
\hline$\# 5$ & $50 \%$ & $25 \%$ & $25 \%$ & $4 \mathrm{ml}$ \\
\hline
\end{tabular}

\section{Results and discussion}

The particle size distribution of the cockles powder is shown in Fig. 3. It shows that particles mean diameter is about 0.6 $\mu \mathrm{m}$. The distribution extends towards larger particles more than it does to smaller particles indicating that production of smaller particles requires a high energy milling for adequately longer time. The XRD pattern of the pure cockles powder is shown in Fig. 4. The main reflections in the XRD spectrum, as indexed in the figure, could easily be associated with the aragonite phase of $\mathrm{CaCO}_{3}$. From the XRD peaks distribution, aragonite seems to be the predominating phase other than calcite and vaterite [2]. Aragonite is known to be more suitable for industrial applications than the other two phases and this shows that cockles shell powder could be utilized for multipurpose use [8]. No other peaks due to presence of impurities in the powder were easily detected confirming the predominance of the aragonite phase. The XRF measurement has been conducted on the prepared cockles powder. Analysis of the XRF measurement shows that the predominant elements composing the powder carbide calcium and less quantities of $\mathrm{Al}, \mathrm{Si}$ and $\mathrm{Sr}$. The estimation of these elements is presented in Table 2. These compositions are in agreement with other results from the literature [4].

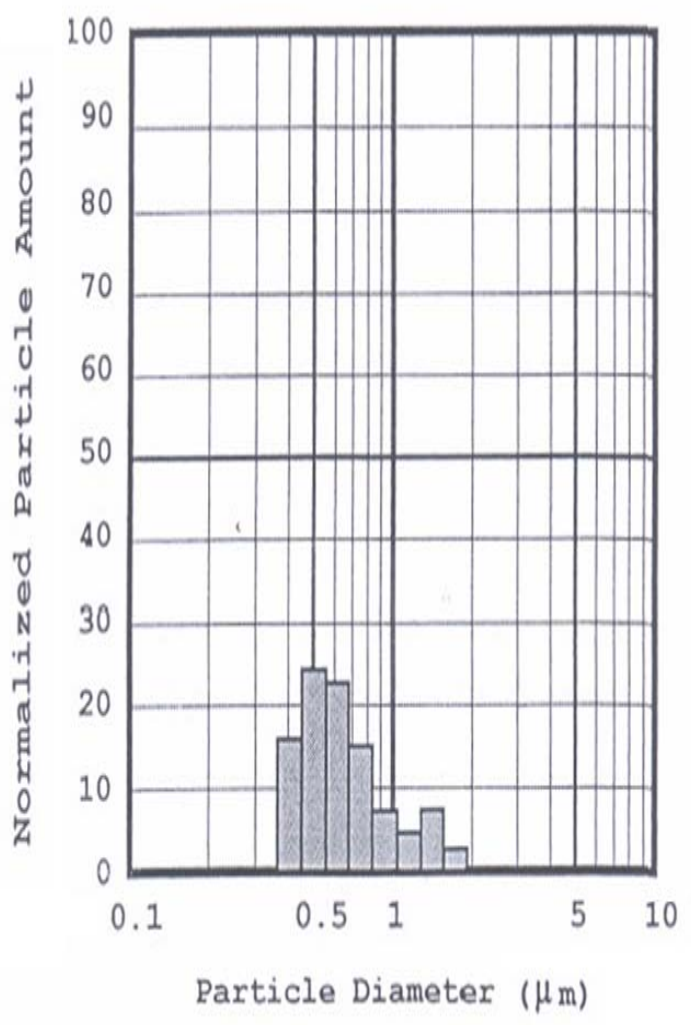

Fig. 3: Particle size distribution of cockles shells powder showing the size species after processing of scrushed shells by ball milling.

The thermal conductivity of the prepared samples is presented in Fig. 5 exhibiting a continuous decrease in value with increase of weight percentage of cockles shells powder in the mortar. 


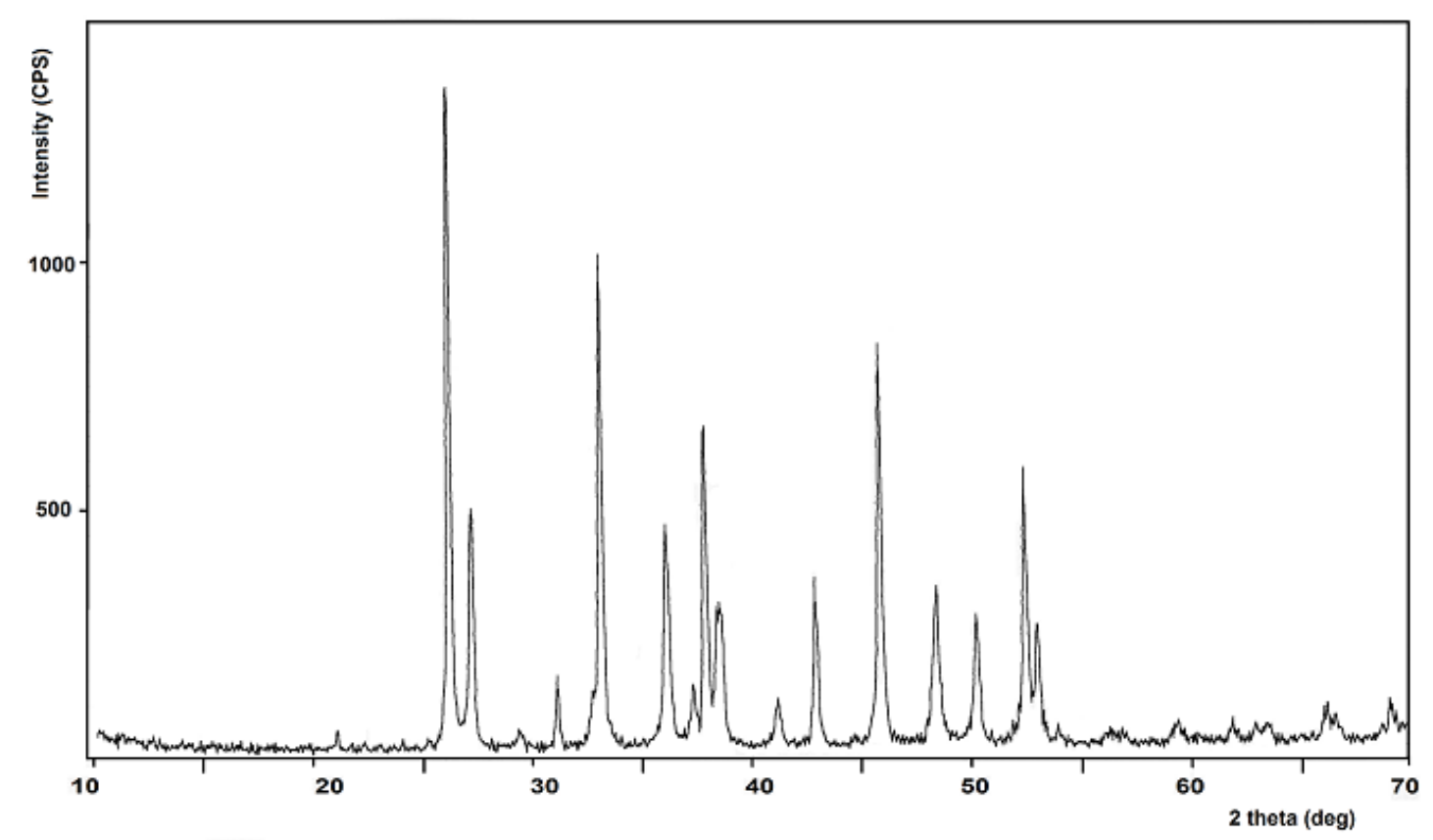

Fig. 4: XRD pattern of cockles shells powder showing predominating aragonite phase in the powder as evidenced from the main reflections.

Table 2: Chemical analysis of cockles shell powder by XRF.

\begin{tabular}{|c|c|c|c|c|c|c|c|}
\hline Element & $\mathrm{CaC}$ & $\mathrm{Al}$ & $\mathrm{Si}$ & $\mathrm{Sr}$ & $\mathrm{Mg}$ & $\mathrm{Na}$ & Others \\
\hline \% ratio & 97.23 & 1.02 & 0.63 & 0.34 & 0.54 & - & 0.24 \\
\hline
\end{tabular}

The increase of cockles powder in the specimen and the associate reduction of cement content led to increase of specimen volume which led to a decrease of specimen density.

The cockles shell powder free specimen exhibited a thermal conductivity of $0.004 \mathrm{~W} / \mathrm{m} . \mathrm{K}$. This value was observed to decrease with the increase of cockles shell powder addition in the specimen until a thermal conductivity of $0.0023 \mathrm{~W} / \mathrm{m} . \mathrm{K}$ was measured at $50 \%$ powder to cement ratio. This means that the cockles shell powder has a lower thermal conductivity than the mortar and that the enhancement of thermal insulation of the specimen is due to the inherent low conductivity of the cockles powder.

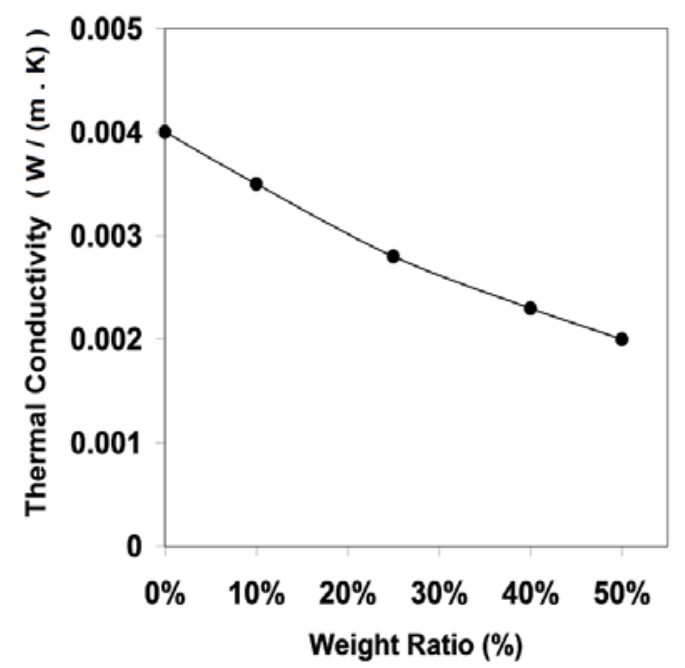

Fig. 5: Thermal conductivity varying with increased weight ratio of the cockles shells powder in the cement mortar samples. 
Fig. 6 shows the hardness of the prepared mortars with cockles powder ratio. It exhibits an increase of specimen hardness with increase of admixture weight ratio. This is attributed to increase of $\mathrm{CaCO}_{3}$ constituent in the mortar leading to increase of its resistance to external indentation.

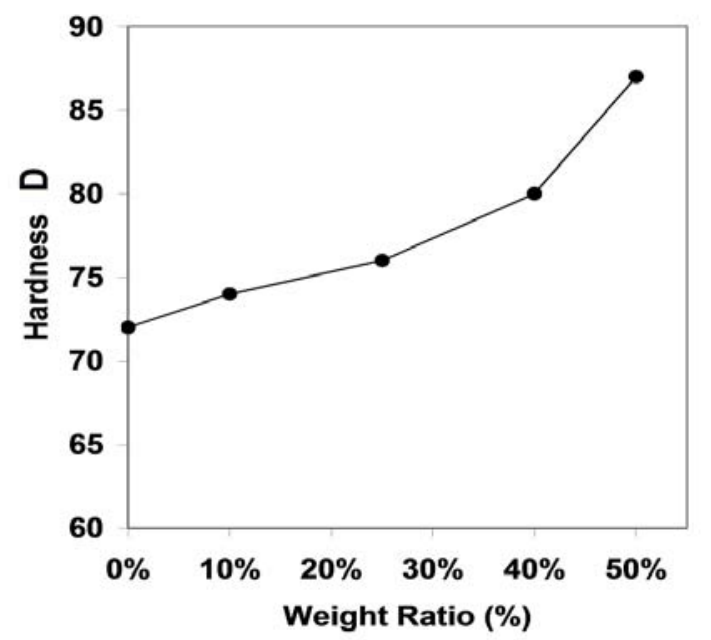

Fig. 6: Hardness of the prepared mortars with increased weight ratio of the cockles shells powder in the specimen.

The compressive strength of the prepared samples is shown in Fig. 7. It shows a general increase of compressive strength with increase of cockles powder ratio. This behavior is believed to relate to the inherent hardness of the powder particles. Each powder particle in the specimen volume is believed to be a center of toleration to external compression. The increase of these toleration centers will therefore result in homogeneous distribution of external force over the entire specimen structure and ultimately to increase of compressive strength. This means that the addition of cockles shell powder led to decline of failure mechanism under external load.

\section{Conclusions}

Cockles shells powder were added as a partial substitute of ordinary Portland cement mortar. Compressive strength and hardness of the cured mortar increased with increasing the powder ratio.

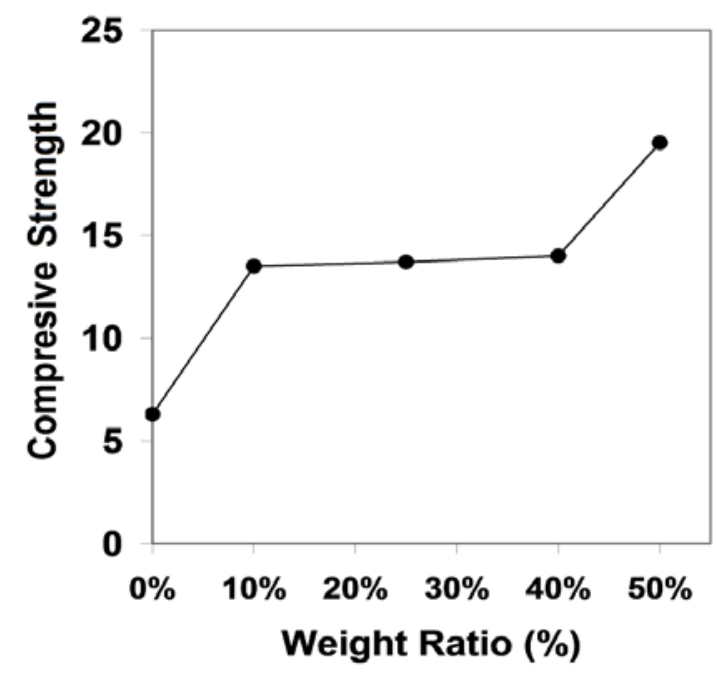

Fig. 7: Compressive strength of the prepared mortars with increased weight ratio of the cockles shells powder in the specimen.

The thermal conductivity of the mortar decreased with the increase of the powder. Results suggest the possibility to use the cockles shells powder in cement mortar for construction and plastering applications.

\section{References}

[1] M. R. R. Hamestera, P.S.Balzera, D. Beckerb, Mater. Res. 15, 2 (2012) 204-208. [2] M.Mohamed, S.Yusup, S. Maitra, J. Eng. Sci. Technol. 7, 1 (2012) 1-10.

[3] P. Lertwattanaruk, N. Makul, C. Siripattarapravat, J. Environ. Manag. 111 (2012) 133-141.

[4] G. L. Yoon, B.T. Kim, B.O Kim, S. H. Han, Waste Management 23 (2003) 825834.

[5] B.Y. Zhong, Q. Zhou, C.F.Chan,Y. Yu, Chinese J. Struc. Chem. 31(2012) 85-92.

[6] K. Muthusamy, N. A. Sabri, Int. J. Sci. Environ. Technol. 1 ,4 (2012) 260-267.

[7] Z. Stojanovic, S. Markovic, TechnicsNew Materials 21(2012) 11-20.

[8] S.Keiko, Y. Tomohiko, T. Masami, J. Mining Mater. Proc. 118, 8 (2002) 553558. 